\title{
Emigration and immigration: Bulgarian dilemmas
}

\begin{abstract}
Bulgaria's specific migration experience is that of a Balkan, post-communist country which is a member of the EU. The different stages of Bulgaria's development mark radical changes in the country's migration processes. In 1989, almost overnight, Bulgaria opened up its borders both for entering and exiting the country. The result was that hundreds of thousands of Bulgarians became emigrants but, at the same time, many foreigners were allowed to become part of Bulgarian society. Joining the EU was another pivotal moment in terms of migration. The free movement of people was only one part of the ensuing changes, with EU membership gradually raising both the country's desirability and its responsibilities. All of a sudden, Bulgaria became one of the EU's external borders and the problems of migration entered the political domain. Politicians had to face the challenges of increasing diversity in the country but also of managing crises that they had not previously encountered. A case in point is the unprecedented wave of refugees in 2013. It is the dilemmas that Bulgaria faces in view of this migration phenomenon that this article will examine.
\end{abstract}

Keywords: emigration, immigration, refugees, labour markets, refugees, asylum seekers, integration policies, political strategies, discrimination, equal opportunities legislation

\section{Introduction}

This study sets out the migration experience of Bulgaria, a Balkan, post-communist country and also a member of the European Union. Bulgaria's experience, as will become apparent, has some specific aspects. This is due, on the one hand, to the fundamental difference in migration governance before and after the changes of 1989; and, on the other, to the number and profile of the people leaving compared to those entering the country. Almost overnight, the country transitioned from a closed society to one which had its borders open for both entry and exit. Over a long period, the attention of society, experts and politicians has been focused on the hundreds of thousands of Bulgarians leaving the country in search of better opportunities. This sidelined the smallscale, but diverse, foreign population which had either recently arrived or been settled in the country for many years.

EU membership has further complicated this profile. European integration has resulted in the increased interest both of foreigners in Bulgaria but also of Bulgarians in the opportunities afforded by the united European space. Politicians have turned their attention to the problems of migration, making migrants the subject of official policy, and have tried to control and direct migration. For example, attracting Bulgarian emi- 
grants, foreigners of Bulgarian origin and highly-qualified migrants was set as a priority.

At the same time, however, the lack of a well-defined policy for integration was a reflection of the lack of understanding of the diversity of arriving immigrants. There was a reliance on the assumption that the majority of permanently-settled foreigners would be of Bulgarian origin, who would have very few problems integrating, whilst the rest would relax comfortably in the welcoming embrace of the host society.

\section{Dynamics of migration processes in Bulgaria}

Any analysis of migration processes invariably needs to take into consideration the communist past of the country. The reason for this, above and beyond any political connotations, is the fundamental difference in the way that migration processes were managed before and after the changes. A particular feature of any communist society is its lack of openness. Typical of migration processes during communism were the high degree of regulatory control and the ceiling imposed on human migration, which applied both to its own citizens crossing borders to move abroad as well as to foreign citizens moving into the country (Krasteva, 2005: 9).

For this reason, under the communist regime, migration was severely restricted and took the following three forms:

- the main group were students from the so-called Third World who were granted scholarships to study at Bulgarian universities

- a very small group was formed by political refugees: mostly people with left-wing convictions from Greece and Turkey

- there is a single example of economic migration - Vietnamese workers, involved mainly in construction in the 80 s. Even this form, which seems as pure labour migration, combines economic and ideological intentions - the Bulgarian communist government responded to the call of its Vietnamese 'brother' to provide employment to some of its surplus labour (Krasteva, Otova and Staikova, 2011).

Immigration, albeit limited, appears to be greater in view of the strict regulation of emigration. This can be clearly seen from the legislation on emigration. At that time, the interest of the state dominated the interest of its citizens (Krasteva, 2008: 64). In 1948, a Law on Bulgarian Citizenship was enacted which stipulated that people leaving the country illegally, and those failing to return within the permitted time, would have their citizenship revoked and all their property confiscated. Two years later, such actions would become punishable by a ten-year prison sentence and a fine of 50000 leva whilst, after 1953, such actions became defined as 'treason toward the Motherland', punishable by the death sentence. The period in the 70 s, following the events in Czechoslovakia, was marked by an upsurge in new measures to combat emigration (Kiryakov, 2011).

Prior to 1989, therefore, emigration was banned as a rule, with the result that Bulgarian citizens moved abroad mostly as refugees. About 20000 Bulgarians left the country between the end of the 1950s and 1989. In contrast to other countries in central and eastern Europe that experienced dramatic outflows of refugees, the figures for Bulgaria show that refugee emigration was stable over time: the annual number of people leaving the country was about 370 (Sultanova, 2006). 
The democratic reforms in Bulgaria thus marked a radical change in the country's migration picture. Actually, it was freedom of movement that was one of the first and most eagerly-consumed freedoms (Krasteva, 2007: 168).

Before I present in greater detail modern-day migration dynamics and trends, it is important to point out that one of the problems faced by analysts of Bulgaria's migration processes is the lack of access to reliable and up-to-date information. Bulgaria is the only EU country that does not have annually collected and comparable statistics on migration. Data provided by institutions is incomplete, not readily available and sometimes contradictory.

Despite this caveat, it can be stated with certainty that Bulgaria is still a predominantly emigration country rather than one of immigration. This means that the number of citizens leaving the country is considerably greater than the number of immigrants who choose Bulgaria as their final destination (Krasteva, Otova and Staikova, 2011).

Emigration has, therefore, been the most frequently-occurring form of migration after the democratic changes in the country. Initially, it was politically or ethnically motivated, but other conditions and factors soon began to influence it and determine its predominantly economic nature (Strategy, 2008-2015).

The different forms of emigration can be summarised as follows (Krasteva, 2013):

- two of them concern mobility among the two biggest minorities: Turks and Roma

- one represents the worst example of forced migration in peaceful times, i.e. the modern form of slavery: trafficking

- the other two represent the two poles of labour migration: of the highly-qualified ('mobile brains'); and of the low-skilled (into '3D' - difficult, dirty and dangerous - work).

According to data for 2011, received from Bulgarian diplomatic missions and summarised by the MFA, the total number of Bulgarians living abroad is $2018792 .{ }^{1} \mathrm{Mi}-$ gration analysts report that emigrants are mainly young people who belong to the 18-34 age group. According to a study by the Open Society Institute from the same year, the main reason for going abroad, standing out clearly amongst all the others, is employment.

It is important to point out that, as of 2014, transitional restrictions on the access of Bulgarian nationals to the EU labour market, which were imposed in an Annex to the Treaty on the Accession of Bulgaria to the EU, have come to an end. For this reason, western EU member countries have been predicting that large groups of Bulgarians will be looking for better fulfilment in work on the EU labour market. It has been forecast that, after the expiry of the restrictions, 400000 Bulgarians will move to the west, with the UK being the most preferred location. In fact, at the end of January 2014, there was no data indicating a higher percentage of Bulgarians migrating to the UK; airline and transport companies report either a reduction or no change in the number of passengers travelling to the UK.

1 Data in respect of 2011, as estimated by Bulgarian diplomatic missions. Data received by NSI and MFA and requested by Eurochicago and the Public Councils of Bulgarians Abroad, in accordance with the Law on Access to Public Information. Available at http://www.eurochicago.com $/ 2012 / 04 / \mathrm{v}$-tchuzhbina/. 
The second form under which migration has unfolded since 1989 is the arrival of foreign citizens in the country. Anna Krasteva's classification of immigration outlines five main directions:

- the largest group with the longest tradition is immigrants from Russia, Ukraine and other countries from the post-Soviet area. This also includes other traditional communities, such as the small in size but well-integrated Armenian community, which has attracted new immigrants searching for a more peaceful political and economic environment than their own

- the most recent but growing group is comprised of EU citizens who, according to European legal norms incorporated into Bulgarian legislation, are not considered foreigners and exercise their right of freedom of movement

- immigration from the near and middle east is part of a tradition nearly half a century old: Syrians, Lebanese, Palestinians, Iraqis, Afghans, etc.

- African immigration is similar to the Arab group in relation to its nearly halfcentury presence in the country. However, its numbers are considerably lower and it is symbolically perceived as different because of the lack of historical contact between Bulgaria and African countries. It must be noted that immigrants from the Maghreb are very few and are a part of the Arab community

- Chinese immigration is one of the most recent and started practically from zero after the opening of the country in the early 90s (Krasteva, Otova and Staikova, 2011).

When calculating the number of immigrants, one has to take into consideration the relative nature of the statistical data. What is clear, though, is that the number of immigrants to Bulgaria is relatively low. The National Strategy of Bulgaria on Migration and Integration (2008-2015) indicates a figure of 55 684. According to data from the National Statistical Institute, obtained on the basis of the previous census from 2011, the number of immigrants in Bulgaria is 36 723. The International Organisation for Migration, however, gives a higher number of foreigners, estimating them to be $1.4 \%$ of the population, i.e. 111000 .

As per the official NSI data, most of the foreigners (83\%) live in the country's cities, and $56 \%$ of them are women. Every second foreign national with permanent Bulgarian residence comes from a European country outside of the European Union. The largest foreign-national group is from Russia - 11991 (65.1\%); followed by citizens from Ukraine - 3064 (16.6\%); the Republic of Macedonia - 1091 (5.9\%); Moldova - 893 $(4.8 \%)$; and Serbia -569 (3.1\%). A significant part of foreign nationals in Bulgaria $(22.9 \%)$ come from the Asian continent, among whom Turkish nationals have the highest relative share $-32.6 \%$; followed by citizens from Armenia - 13.9\%; and from China $-8.9 \%$.

At the time of the 2011 census, 8444 (23\%) of all foreign nationals with permanent residence in Bulgaria are EU citizens. Among these, the largest number are UK citizens -2605 (30.9\%); followed by citizens from Greece - 1253 (14.8\%); Germany - 848 (10\%); Poland - 819 (9.7\%); and Italy - 456 (5.4\%).

At the time of the census, 22152 people ( $0.3 \%$ of the country's population) declared dual citizenship, i.e. of Bulgaria and one other country. Among these, individuals of dual Bulgarian-Russian citizenship took the largest relative share - 5257 (23.7\%); 
followed by individuals of dual Bulgarian-Turkish nationality - 4282 (19.3\%); and those with dual Bulgarian-USA citizenship - 1725 (7.8\%).

Despite the relative nature of the data, several trends can be outlined:

- after Bulgaria joined NATO in 2004, migration inflows to the country started to increase, reaching their peak in 2007, when Bulgaria joined the EU

- in recent years, the number of foreigners with long-term or permanent residence has been growing at a slow, but steady, rate. Among foreigners with long-term and permanent residence status, the highest number of third-country citizens are from Turkey, followed by citizens from Macedonia, Russia and Ukraine. In actual fact, data for 2012 indicate an increase of $12.4 \%$ in the number of permits for long-term residence (16 827) for third-country citizens, as well as a negligible increase in the number of permits from the same for permanent residence (2 792). The largest number of such permits was granted to citizens from Turkey, the Russian Federation, Moldova and Macedonia (Annual Report on Implementation of the National Strategy on Migration, Asylum and Integration (2011-2020))

- a similar trend can be observed in relation to some west European EU member countries - the figures indicate a steady increase in interest from among their citizens. The number of UK citizens granted long-term residence status grows by more than $100 \%$ every year. The large number of German citizens remains constant, while there is a definite trend for French and Italian citizens to seek long-term residence status in Bulgaria. Compared to 2011, there was an increase by $24.3 \%$ and 2.5 times respectively in both the permits granted in 2012 for long-term (5 428) and for permanent residence (4 368) for citizens from the EU, EEA and the Swiss confederation. Such long-term residence permits were granted primarily to citizens from Greece, the UK, Germany, Italy and Romania. The largest number of permanent residence permits was granted to citizens from the UK, Germany, Greece, Italy and Poland (Annual Report on Implementation of the National Strategy on Migration, Asylum and Integration (2011-2020)).

Bulgaria's third form of migration is refugees and asylum-seekers. Prior to 1989, as we have remarked already, Bulgarians moved abroad mainly as political emigrants. An interesting fact is that, to this day, Bulgarians abroad continue to apply for asylum, even though the country's democracy has long been recognised, as evidenced by its Euro-Atlantic and EU memberships as well as by being a party to numerous international documents in the area of human rights.

Despite all this, after 1989, three main periods can be distinguished on the basis of the number of applications; the changes in legislation; and the variations in recognising refugee status or awarding temporary forms of protection (Sultanova, 2006).

The first period (1989-1993) relates to the opening of Bulgaria's borders for travel. This led to a huge increase in both the number of emigrants as well as applications for asylum. The number of asylum-seekers grew from 562 in 1988 to 7268 in 1989. Typical of this period is the continuing reduction in the number of asylum applications that were granted. The end of this period is marked by Bulgaria's signing of the Geneva Convention in April 1993 and the New York Protocol in May of the same year. The result of these formal ties, which were new for Bulgaria, as well as its democratic changes and the commitment of host countries to limit the inflows of asylum-seekers, 
was that the majority of west European countries included Bulgaria in their lists of secure countries.

The second period (1994-2000) is characterised by relative stability in the annual number of applications for asylum. There was a decrease in asylum applications after 1994, when they reached a peak, registering a total of 23300 applications across the whole period. During this period, applications from Bulgarian nationals were either granted by means of an expedited procedure or were declared as being unfounded immediately after submission. Therefore, the number of Bulgarians who were granted refugee status was close to nil.

During the third period (2001 onwards), the number of submitted applications for asylum remained high, even though Bulgarians could no longer be granted refugee status.

The UNHCR database records the number, albeit it is very low, of Bulgarians who continue to apply for refugee status. Estimates by experts show that the majority of asylum-seekers are from a Roma background.

After signing the Geneva Convention in 1993, Bulgaria joined the countries that can grant asylum and undertook international responsibilities in this respect. In the following years, the number of refugees and asylum-seekers in Bulgaria rose, but still remained low at about 1000 applications received every year. The situation changed in 2013, when more than 7000 people applied for asylum in Bulgaria. The majority of them came from Syria where, as a result of the crisis, more than two million citizens became refugees in other countries (as per data from SAR).

The unprecedented peak in asylum-seekers in Bulgaria sees those arriving in the country confronted by institutional collapse, political and media ostracism and growing social tension. In a very short time, reception facilities have been filled way over capacity; the procedures for examination of applications has been hampered by difficulties during the proceedings; and available expertise has proven to be extremely limited. All this is happening against a background of a public debate dominated by an extreme populist discourse. It should be pointed out that, over the years, the attention of the media has been focused much more on refugees and asylum-seekers rather than on economic migrants. This has not changed with the increase in the urgency and scale of the problem, but asylum-seekers are often referred to as offenders who have 'entered the country illegally'. This improper and negative image is much more frequently being projected on the general public, thus promoting a negative attitude towards foreigners on the whole (Nonchev, 2013).

At the beginning of 2014, UNHCR issued a report on the country's systemic deficiencies in the implementation of the legal provisions, policies and practices for providing international protection for refugees. It concludes that conditions in Bulgaria need to be fundamentally improved in order to reach international and European standards, and it recommends that the practice of transferring asylum-seekers back to Bulgaria on the basis of the Dublin Regulation should be stopped (UNHCR, 2014). This is a clear signal in respect of the inability of the Bulgarian state to deal adequately with the crisis that has arisen. Politicians are primarily trying to find ways to limit the entry of new people into the country rather than find solutions to the acute problems faced by those who are already on its territory. 
Nevertheless, a bright ray of hope in the midst of this dismal situation is the largescale civil activity aimed at helping newly-arrived refugees.

\section{Political vision and strategic documents}

One of the characteristics of Bulgarian migration policy is its late entrance into government priorities, followed by a rapid acceleration of the process to develop strategic programmes. It was only five years ago that migration was given the status of public policy for which the state needed to have a strategic vision. In 2008, the first Strategy for Immigration and Integration was adopted. As early as 2010, work on the development of a new migration strategy was started, which was finalised at the beginning of 2011 (Krasteva, Otova and Staikova, 2011).

The initial stages of working out the vision of the strategic documents and their further development were delayed both by the socio-political processes unfolding in Bulgaria and by the country's membership of the EU. It is no accident that the first strategy was adopted one year after the country joined the EU. The second strategy was developed in response, on the one hand, to the economic crisis which prevailed over the majority of public policies; and, on the other, to the preparations of the country for entry to Schengen.

The key difference between the two documents is in a redefinition of the main priorities of migration policy. The 2008 strategy focuses mainly on economic migration and the integration of foreign citizens in Bulgaria. In that strategy, one can read the following:

...Bulgaria has started turning irreversibly into a host country for immigrants. This is also a result of the good economic indicators, low unemployment rate and business opportunities available in the country. (National Strategy on Migration and Integration, 2008-2015)

This strategy was written during a period of economic growth, so it expresses the political vision on immigration in its most positive light and regards it as a factor in economic development:

Bulgarian migration policy is applied in support of economic development. (Strategy, 2008-2015)

Several years later, the new National Strategy on Migration, Asylum and Integration (2011-2020) is focused primarily on the problems of security. The reason for this shift is clearly defined:

Bulgaria 's joining of the Schengen Area increases the country's commitments for the protection of the external border of the Union and creates a new environment requiring a focus on counteracting illegal migration in the context of national and European security. (Strategy, 2011-2020)

The second strategy nevertheless retains a positive attitude towards migration. It reiterates the determination that migration can be a well-managed process so that it 
may contribute to the development of the national labour market and to the economic growth of the EU (Strategy, 2011-2020).

Despite the late entry of migration policy into politics, the political vision on migration follows the latest trends in this area and its typically western features are also applicable to Bulgaria. A strong focus is placed on selective policies, i.e. each country declares what kind of immigrants it would like to prioritise. Bulgaria does not implement immigration policies which are based on a points system or are market-oriented, ${ }^{2}$ but both strategies clearly express the type of immigrants politicians would most like to attract:

- Bulgarian citizens and foreigners of Bulgarian origin

- highly-qualified migrants.

The degree to which these groups of migrants are preferred is evident in that, in the current Strategy's section on priorities, both groups are amalgamated into one:

Attracting highly-qualified Bulgarian nationals - emigrants, as well as foreigners of Bulgarian origin - permanently to establish and settle in the country. (Strategy, 2011-2020)

Encouraging Bulgarian citizens and foreigners of Bulgarian origin to settle in the country is also reflected in the existing legislation. For example, Bulgarian origin is one of the grounds on which permanent resident status in the country can be obtained. In this respect, the procedure has been simplified and its cost reduced. Foreigners of Bulgarian origin have to pay only $5 \%$ of the regular fees, i.e. they have to pay 50 leva instead of 1000 leva. There are similar incentives to enable individuals of Bulgarian origin to adopt Bulgarian citizenship.

In order to attract such citizens, the first Strategy from 2008 envisages the introduction of a so-called 'green card', a document giving the same rights as those applying to Bulgarian citizens. It is aimed at creating opportunities for individuals of Bulgarian origin, but currently citizens of other countries, to settle permanently in Bulgaria as a first step to obtaining Bulgarian citizenship. This instrument has been laid down in the draft of a new Law on Bulgarian Communities outside the Republic of Bulgaria.

The argument for this approach is a cultural one. The representatives of the historical diaspora are considered to be linguistically and culturally the closest; hence their integration is taken as natural: individuals of Bulgarian origin:

Would have no problem integrating into society because of their knowledge of the Bulgarian language, customs and culture. (Strategy, 2008-2015)

This approach is positive, but seems located more in the sphere of wishful thinking than that of the analytical. It unfolds in a primordial perspective, stemming from the premise of strong identities by origin and individual migration projects whose aim is to manifest these identities - for the diaspora representatives who want to settle in Bulgaria in order to return to their land of origin and contribute to its development. However, we know from theory, while practice proves it, that the main motivation for

2 Despite this, trade associations submit to the National Council on Labour Migration their proposals for annual trade quotas for foreign workers. 
migration is pragmatic; that identities are instrumentalised to achieve not cultural but economic goals (Krasteva, Otova and Staikova, 2011).

As regards increasing the opportunities to attract highly-qualified migrants, representing the other target group, not much has been done. The only provision that can be regarded as an incentive for people to come into the country is the introduction of the 'EU Blue Card' into Bulgarian legislation. By the end of 2012, fourteen permits for exercising the rights of a highly-qualified employee had been granted, to citizens from Russia, Turkey, Ukraine, Iran, India, USA, China, Armenia, Serbia and Canada. These permits were issued in respect of engineers, lawyers, economists and IT programmers.

In conclusion, it can be noted that the political vision on migration is far from being fully realised, especially with regard to the issue of immigrants' integration.

\section{Integration policies in Bulgaria}

The complexity of the processes of migration and the integration of immigrants in Europe has created a diversity of models and specific experiences in each country, and in the regions and even cities of each one. Each country has its own migration history, established immigrant communities, political practices and traditions for communicating with the host society (Nonchev, 2010). Regrettably, Bulgaria lacks a clearly-defined policy on integration and, in this area, declarations of intentions abound which, however, have not been supported by specific actions.

In spite of this, the following main conclusions can be drawn:

- policy on the integration of immigrants is implemented in line with the EU's Common Basic Principles for Immigrant Integration

- one of its indisputable achievements is the existing legislation on equal opportunities and non-discrimination, which is well-developed and fully aligned with European standards. The Law on Protection against Discrimination transposes in full the European Equality Directives, regulating the protection of all those living on the territory of the Republic of Bulgaria against all forms of discrimination, while also contributing to the prevention of discrimination and the laying down of equal opportunity measures

- policy on immigrant integration is implemented with support from the European Integration Fund. Under the European Fund, projects for the integration of thirdcountry nationals, via several information and integration centres whose aim is to assist newly-arriving foreigners by providing them with the information they require during their stay in the country, have been opened in Sofia and the three other largest Bulgarian cities.

More detailed information on integration policies can be found from the Migrant Integration Policy Index (MIPEX). ${ }^{3}$

MIPEX analyses seven areas of a country's immigrant integration policy - labour market mobility; education; family reunification; political participation; long-term residence; access to nationality; and anti-discrimination. The Index measures the quality

3 The Migrant Integration Policy Index (MIPEX) provides a comprehensive tool which can be used to assess and compare policies on the integration of third-country nationals. Its official site is at: http://www.mipex.eu/. 
and effectiveness of policies from a comparative and timeline point of view. On the basis of its analysis, Bulgaria's policies on immigrant integration for 2011 have been assessed as moderately favourable, while the country is ranked in $26^{\text {th }}$ place among 31 countries from Europe and north America.

For example, in the area of labour market mobility for third-country nationals, Bulgaria received a relatively low score in terms of job opportunities. This is due to the difficulties immigrants face in respect of starting work immediately. Once a work permit has been issued, immigrants' access to positions in the private, and partially in the public, sector received a relatively high score. There is, however, a lack of general and targeted state support for foreigners to obtain jobs commensurate with their qualifications. The analysis points out that immigrants' foreign qualifications might not be recognised and that they may end up wasting a lot of time trying to reach top-level positions in line with their competences.

In relation to the labour market, the Bulgarian state outlines the need to attain a higher degree of integration of foreign citizens. This can be achieved by providing assistance to immigrants to obtain the relevant skills and qualifications which meet the needs of the labour market. The Annual Report on the Implementation of the National Strategy on Migration, Asylum and Integration (2011-2020) points out that the Employment Agency offers mediation services for providing employment and training for all job-seekers, including foreigners, registered at one of the regional offices of the Labour Office Directorate. All registered individuals have equal access to the mediation services and, in this respect, there must be no direct or indirect discrimination, privileges or restrictions on the basis of nationality, origin, sex, race, etc.

In this connection, the data indicates that, in 2012, 860 foreigners were registered at Labour Offices. Of these, 845 had the right to permanent residence while 15 had refugee or humanitarian status. Foreigners registered at Labour Offices were from 29 countries, the largest number being from Russia (624) and Ukraine (116), all of them having permanent resident status. The individuals with refugee or humanitarian status were from six countries - four from Iran; three each from Afghanistan, Ethiopia and Iraq; and one each from Armenia and Georgia. Of all registered individuals, 406 were over the age of 50, while 209 foreigners had primary or lower education. The total number of employed foreigners registered at Labour Offices was 198, 142 of them being women. Labour Offices had assisted 139 individuals to obtain jobs, 23 of these being jobs on employment programmes. Seventeen individuals, 16 of them women, were included on training programmes.

Education is another important area of integration. According to MIPEX, Bulgaria has one of the lowest scores, taking $30^{\text {th }}$ place in the table, i.e. the lowest but one. One of the reasons for this is that temporary and undocumented immigrants have to pay fees for their children's education. Another significant reason is the lack of special programmes for immigrant pupils: children are educated on standardised Bulgarian programmes which cannot meet their specific needs. According to the Annual Report on Implementation of the National Strategy on Migration, Asylum and Integration (2011-2020), the area of providing quality education for immigrants' children is one of the areas in which there has been no progress on achieving the set targets. 
Political participation is another area of integration. In this respect, the degree of integration is extremely low, since third-country citizens are practically excluded from democratic life in Bulgaria, not being able to vote or stand in any election. Besides, there is no evidence of immigrant bodies being a part of integration governance or of representing the interests of immigrants.

In many cases, successful policies have been developed in the non-government sector and good practices have frequently been implemented at local level. This is the place to point out that, in Bulgaria, there have been successful projects for the integration of third-country nationals which have been financed by the European Integration Fund.

The key findings in respect of Bulgaria's integration policies point to a lack of vision and political will and commitment. One possible reason is the large number of ministries and departments who are involved in different ways in migration governance, but no single government institution has explicit responsibility for the social integration of immigrants in the country. In its 2006 report, the Bulgarian Helsinki Committee is much more blunt in its assessment:

In practice, there is no policy for the social integration of immigrants. (BHC, 2006: 32)

\section{Conclusion}

Our analysis has clearly set out the characteristics of the phenomenon of migration in Bulgaria. It also details its complexity and has presented its contemporary dimensions. This examination has illustrated that Bulgaria's migration profile is transitioning into a normal model of migration and is getting much closer to the typical European model. Even though emigration still dominates, it is mainly driven by economic factors, whilst political and ethnic factors remain only as examples from past history. On the other hand, it is the history of emigration that gives grounds to define Bulgaria's migration profile as per Baldwin-Edwards's well-known typology of Balkans forms of migration: forced migration; ethnic migration; trafficking; and temporary migration. We have previously shown that the only divergence here is in respect of forced migration, but there have been examples of all the other forms, while trafficking and temporary migration continue to be phenomena in today's world.

On the other hand, it is the characteristics of immigration that bring the Bulgarian migration profile much closer to the European one. Bulgaria's accession to the EU is adding new colours to the migration picture - foreigners from many and various places have started to arrive in the country, either to stay temporarily or to settle permanently. The result is that the country's foreign population is by no means limited to immigrants of Bulgarian origin. Citizens from western Europe, from Asia, from neighbouring countries, etc. are arriving in Bulgaria.

On the basis of the available empirical data, the conclusion can be drawn that foreign citizens living in Bulgaria are mainly economically active, well-educated and financially secure individuals, and that they are making a contribution to the country's development. It is important to point out that politicians have yet to recognise this hidden potential; a fact which is clearly evident from their under-developed and poorly-defined integration policies. 


\section{References}

Baldwin-Edwards, M (2006) Patterns of migration in the Balkans UEHR Working papers No. 9.

BHC (2006) Research into the rights of migrants in Bulgaria from a human rights perspective Final Report: 32. Available at: http://issuu.com/bghelsinki/docs/migr antsrightsreporteng-1-1- [last accessed 26 January 2014].

Kirjakov, Boyko (2011) Statement of the conference Bulgarian Communism - two decades later available at: http://www.dnevnik.bg/bulgaria/2011/11/10/1201555 bulgarskiiat_komunizum_sreshtu_bulgarskata_emigraciia/ [last accessed on $2 \overline{6}$ January 2014] (in Bulgarian).

Krasteva, A (Ed.) (2005) Immigration in Bulgaria Sofia: International Center for Minority Studies and Intercultural Relations.

Krasteva, Anna (2007) 'Strengthening cross-border co-operation in the Western Balkans regarding migration management - Bulgaria' in: Migration flows in South Eastern Europe, a compendium of national perspectives Belgrade, pp. 163-193.

Krasteva, Anna (2008) 'In search of new opportunities: emigration from and immigration to Bulgaria' in: Anna Krasteva (Ed.) Immigration and integration: European experiences Sofia: MWF, p. 64.

Krasteva, Anna (2013) 'Bulgarian migration profile' in: Blog for politics, e-citizenship and migration available at: http://annakrasteva.wordpress.com/2013/03/21/bulgar ian-migration-profile/ [last accessed on 26 January 2014].

Kristeva, Anna, Ildiko Otova and Evelina Staikova (2011) Satisfying labor demand through migration in Bulgaria: 2004-2009 European Migration Network (EMN) (in Bulgarian).

National Strategy of the Republic of Bulgaria on Migration and Integration (2008-2015) (in Bulgarian).

National Strategy on Migration, Asylum and Integration (2011-2020) (in Bulgarian).

Nonchev, Andrei et al. (2010) Indicators, methods and techniques for monitoring and evaluating the implementation of the objectives and measures for the integration of third country nationals Analytical Report Sofia: CID, available at: www.csd.b $\mathrm{g} /$ fileSrc.php?id=20136 (last accessed on 26 January 2014).

Nonchev, Andrei (2013) Immigrants - problem or potential for Bulgarian society available at: http://fakti.bg/mnenia/58443-imigrantite-problem-ili-potencial-za-ba lgarskoto-obshtestvo (in Bulgarian) [last accessed on 26 January 2014].

NSI (2011) Population with foreign citizenship by countries of origin available at: http://censusresults.nsi.bg/Census/Reports/2/2/R11.aspx (in Bulgarian).

Otova, Ildiko (2012) 'Migration, integration, cities: European contexts' Sociological Problems 1-2: 222-237 (in Bulgarian).

Soultanova, Ralitsa (2006) 'Bulgarians as refugees' in Anna Krasteva (Ed.) Figures of refugees Sofia: NBU, pp. 151-178 (in Bulgarian). 
Staikova, Evelina and T. Trifonova (2010) Immigrants in Bulgaria, B: Trends in crossborder labor migration and free movement of people - Effects for Bulgaria Sofia: Open Society Institute.

Vankova, Zvezda (2012) 'Bulgaria in the international index of integration policies for migrants' in: Sociological Problems 1-2 (in Bulgarian). 